Research Article

\title{
Bedding Plane Effects on Mechanical Behavior of Surrounding Rock in Mountain Tunneling
}

\author{
Shuang You $\mathbb{D},{ }^{1,2}$ Jincui Sun $\mathbb{D},{ }^{1}$ and Hongtao Wang ${ }^{1}$ \\ ${ }^{1}$ School of Civil and Resource Engineering, University of Science and Technology Beijing, Beijing 100083, China \\ ${ }^{2}$ Beijing Key Laboratory of Urban Underground Space Engineering, University of Science and Technology Beijing, \\ Beijing 100083, China \\ Correspondence should be addressed to Jincui Sun; sunjincui0922@163.com
}

Received 29 July 2021; Revised 23 August 2021; Accepted 24 September 2021; Published 13 October 2021

Academic Editor: Fan Feng

Copyright (C) 2021 Shuang You et al. This is an open access article distributed under the Creative Commons Attribution License, which permits unrestricted use, distribution, and reproduction in any medium, provided the original work is properly cited.

\begin{abstract}
The layered rock showed the characteristics in Mountain tunnel, Yunnan. A series of uniaxial compression tests and variable angle shear tests were carried out, and the aim was to investigate the effect of the bedding on its mechanical parameters and failure modes. The test results show that the uniaxial compressive strength, elastic modulus, and Poisson's ratio of layered rock present a $\mathrm{U}$-shaped distribution with the increase in bedding orientation from $0^{\circ}$ to $90^{\circ}$. All of them have a maximum when the bedding orientation is $0^{\circ}$ and a minimum when the bedding orientation is $45^{\circ}$. The failure modes of layered rock can be summarized into three types: the fracture tensile failure parallel to the weak plane of bedding; the shear slip failure along bedding weak plane; and tension-shear composite failure between bedding weak plane and matrix. Based on the testing data and analysis results, it can be concluded that the layered rock specimen with different bedding orientations is an important reason for the anisotropy of mechanical parameters and failure modes.
\end{abstract}

\section{Introduction}

The layered rock is usually interbedded with soft and hard rock. The main structural plane is bedding plane, and there are weak structural planes such as interlayer dislocation and argillaceous intercalation. The deformation and failure are mainly controlled by geology and rock combination. The heterogeneity of the rock with bedding plane is enhanced, and the minerals on the internal plane are easy to form weak structural plane. When there is bedding plane in the rock mass, it makes the axial strain larger. In the construction of tunnels in layered rock, the anisotropy of surrounding rock is very important to the safety and stability $[1,2]$. When drilling in layered rock formation, the permeability of fractures between bedding is much higher than that of rock matrix. Fluid is easy to immerse into the formation along the microfractures between bedding, which changes the effective stress state around the well, reducing the strength of layered rock and affecting the stability of wellbore during drilling [3]. Therefore, it is of great engineering application value to study that bedding orientation effects on mechanical parameters and failure mode of layered rock.

At present, many scholars have obtained lots of achievements in the study of the effect of bedding orientation on layered rock. Wang et al. [4] conducted Brazilian splitting tests on slates with different bedding orientations and clarified the failure mechanism by analyzing the changes of tensile strength and failure behavior. Yang et al. [5] carried out the direct shear test on layered rock specimens, and the results show that the bedding orientation has a significant effect on the cohesion and internal friction angle of rock. Xia et al. [6] carried out the direct shear test of layered rock, and the results show that with the increase in the bedding orientation, the shear strength index of rock mass first increases, then decreases, and finally increases. Fan et al. [7] used theoretical analysis and numerical simulation to study the macroscopic mechanical behavior of layered rock and discussed transversely the isotropy strength criterion of layered rock. Li et al. [8] without considering the influence of $c$ and $\varphi$, when the bedding orientation of layered 
rock is $45^{\circ}$, the crack initiation and propagation are most likely to occur; when $\beta$ is known, the corresponding fracture toughness value can be obtained. Liu et al. [9] conducted uniaxial compression tests to show that there are two forms of compression failure of layered rock: compression shear failure occurs from the interior of layered rock and the shear plane is rough; the surface of layered rock is smooth, and sliding failure occurs along the bedding plane. Gao et al. [10] conducted compressive and tensile strength tests of shale and analyzed the transversely isotropy characteristics of shale specimens. The results show that the tensile strength perpendicular to the bedding plane is about 300-360 times that parallel to the bedding plane, and the velocity anisotropy ratio of compression wave is about 1.3-1.4. Liu et al. [11] obtained three failure mechanisms of layered rock: tensile failure along bedding plane, shear failure along bedding plane, and tensile failure of matrix in the direct tensile test. Through numerical simulation, Tan et al. $[12,13]$ analyzed the stability of layered rock with different bedding directions, the range of surrounding rock loose area, and the key parts of instability, which has important theoretical significance for further understanding the instability mechanism of tunnel in layered rock. Xia et al. [14] carried out numerical simulation of rock with different bedding orientations under the uniaxial compression test and obtained that when the bedding bond strength is very different from the bedrock, the effect of bedding can be ignored, while when the two are close, bedding has a great influence. Fu et al. [15] conducted the uniaxial compression test on layered rock and obtained that there are three failure forms of rock mass with the change of bedding orientation. Yuan et al. [16] studied the influence of loading rate on the mechanical properties of layered rock and obtained that the total energy, elastic strain energy, and dissipated energy of rock mass after exceeding the critical value of loading rate have S-shaped curve variation law similar to the strength.

In this paper, the transverse isotropy and anisotropy of layered rocks in Mountain tunnel, Yunnan, were studied. Through the uniaxial compression test and variable angle shear test, the variation law of peak strength and mechanical parameters of layered rocks with different bedding orientations was explored, and the failure modes were classified and analyzed. When layered rocks were treated as transversely isotropic bodies, five independent material parameters were determined. The relationship among bedding orientation, cohesion, and internal friction angle was established.

\section{Calculation Principle of Transversely Isotropic Constitutive Model Parameters}

The physical parameters, mechanical parameters, and hydraulic parameters of rock mass usually show anisotropy, and these parameters will change with the change of direction. Although layered rock shows different mechanical properties at different bedding orientations, it is usually regarded as transversely isotropic in practical engineering applications. As shown in Figure 1, the coordinate system $X$, $Y$, and $Z$ is set, where the $Z$ axis is the longitudinal axis

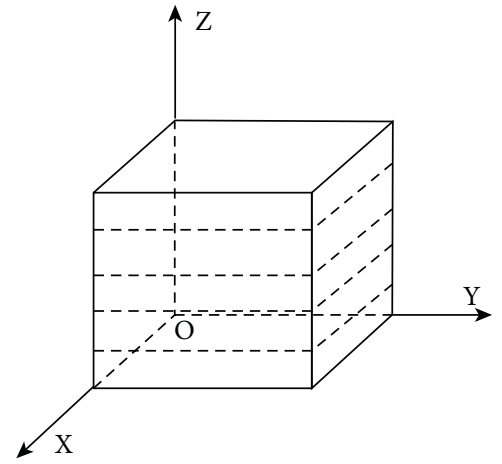

FIGURE 1: Schematic diagram of transversely isotropic material in the global coordinate system.

direction of the specimen. In the general coordinate system, the stress-strain relationship is as follows [17]:

$$
\varepsilon=S \sigma,
$$

where $\varepsilon$ is the strain tensor, $S$ is the flexibility matrix, and $\sigma$ is the stress tensor. The matrix is expressed as follows:

$$
\left[\begin{array}{c}
\varepsilon_{x} \\
\varepsilon_{y} \\
\varepsilon_{z} \\
y_{x y} \\
y_{y z} \\
y_{z x}
\end{array}\right]=\left[\begin{array}{rrrrrr}
\frac{1}{E_{1}} & -\frac{v_{1}}{E_{1}} & -\frac{v_{2}}{E_{2}} & & \\
-\frac{v_{1}}{E_{1}} & \frac{1}{E_{1}} & -\frac{v_{2}}{E_{2}} & 0 & \\
-\frac{v_{2}}{E_{2}} & -\frac{v_{2}}{E_{2}} & \frac{1}{E_{2}} & & & \\
& & & \frac{2\left(1+v_{1}\right)}{E_{1}} & \\
& & & & & \\
& & & & \frac{1}{G_{12}} & \\
& & & & & \\
& & & & & \frac{1}{G_{12}}
\end{array}\right] .
$$

In equation (2), there are five independent elastic parameters, namely, $E_{1}, E_{2}, v_{1}, v_{2}$, and $G_{12}$, which together represent the deformation performance. $E_{1}$ and $E_{2}$ are the elastic modulus in the transversely isotropic plane and the direction perpendicular to the plane, respectively; Poisson's ratios $v_{1}$ and $v_{2}$ describe the reflection of the transverse strain in the transversely isotropic plane and the stress parallel or perpendicular to the isotropic plane, respectively; $G_{12}$ is the shear modulus perpendicular to the transversely isotropic plane.

In this experiment, $v_{1}$ and $v_{2}$ are Poisson's ratio when the bedding orientation is $90^{\circ}$ and $0^{\circ}$, respectively. In order to determine these five independent material parameters, at least one specimen with any bedding orientation is needed in 
addition to the specimens with $0^{\circ}$ and $90^{\circ}$ bedding orientation. Therefore, the sample with $30^{\circ}$ bedding orientation is selected. The formula of the elastic modulus with $\beta$ between loading direction and bedding plane is as follows [17]:

$$
\frac{1}{E_{\beta}}=\frac{\sin ^{4} \beta}{E_{1}}+\left(\frac{1}{G_{12}}-\frac{2 v_{1}}{E_{1}}\right) \sin ^{2} \beta \cos ^{2} \beta+\frac{\cos ^{4} \beta}{E_{2}},
$$

where $E_{\beta}$ is the elastic modulus when the angle between loading direction and bedding plane is $\beta$.

\section{Experimental Tests}

3.1. Specimen Preparation. The rock core used in the test is taken from the tunnel of Xiangli Expressway Tunnel in Yunnan Province. The structural characteristics of the rock mass are plate-shaped or flaky-shaped. There is a small amount of clay and silty filler in the rock fracture (as shown in Figure 2). The specimens were taken from the whole large rock mass and cut into the whole cube. In order to study the anisotropic characteristics of rock mass under different bedding orientations, core drilling sampling was carried out from five directions of $0^{\circ}, 30^{\circ}, 45^{\circ}, 60^{\circ}$, and $90^{\circ}$, respectively. The schematic diagram of core drilling sampling is shown in Figure 3.

According to the specific requirements, the specimens used in the test were processed into test blocks of different sizes and shapes by drilling and grinding machines. The number of test blocks in each group should not be less than 3. The standard specimens were made as follows: $\Phi 25 \times 50 \mathrm{~mm}$ cylinder specimens were used for the uniaxial compression test (as shown in Figure 4), and cube specimens with $30 \mathrm{~mm}$ side length were used for the variable angle shear test (as shown in Figure 5).

3.2. Test Equipment and Scheme. The uniaxial compression test and variable angle shear test were carried out on cylinder specimens and cube specimens, respectively. GAW-2000 electrohydraulic servocontrolled uniaxial test machine and hydraulic screen display universal testing machine (a set of $20^{\circ}, 30^{\circ}$, and $40^{\circ}$ variable angle shear fixture) are used, and these equipments have stable performance and high test accuracy. In the uniaxial compression test, the displacement control mode was adopted, and the axial load was applied to the specimens at the loading speed of $0.015 \mathrm{~mm} / \mathrm{min}$, and the stress-strain curve was collected at the same time. In the variable angle shear test, the stress control method was used to apply the load at the loading rate of $100 \mathrm{~N} / \mathrm{s}$ until the specimens failed, and the failure load $\mathrm{P}$ was recorded, as shown in Figure 6.

\section{Analysis of Test Results}

4.1. Influence of Bedding Structure on Rock Mechanical Parameters. The results of uniaxial compression tests of layered rock with different bedding orientations are shown in Figure 7.

It can be seen from Figure 7(a) that when the bedding orientation changes from $0^{\circ}$ to $90^{\circ}$, the peak strength of layered rock first decreases and then increases. The peak

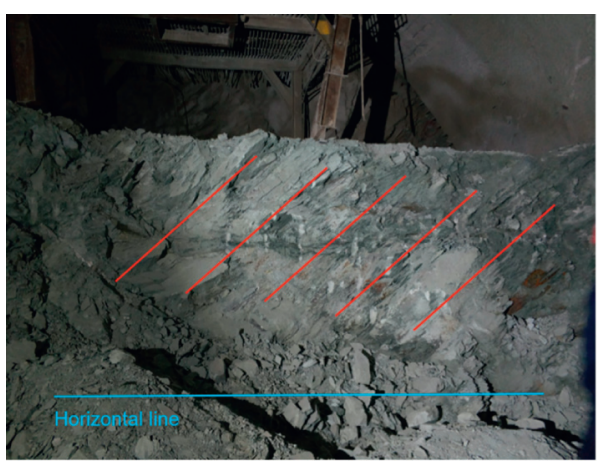

Figure 2: Bedding structure of surrounding rock of Xiangli Expressway Tunnel in Yunnan Province.

strength decreases between $0^{\circ}$ and $45^{\circ}$ and increases between $45^{\circ}$ and $90^{\circ}$. On the whole, there is a "U-shaped" change trend of high on both sides and low in the middle. The peak strength is the highest at $0^{\circ}$ and the lowest at $45^{\circ}$. The results are consistent with the previous layered rock test results [18-20]. The maximum peak strength is more than three times of the minimum peak strength. Therefore, the peak strength of layered rock is affected by bedding orientation, showing obvious anisotropy characteristics.

According to the concept of "anisotropy ratio" proposed by J. Singh et al. [21] in 1989, the anisotropy ratio of peak strength of layered rock is defined as follows:

$$
R_{c}=\frac{\sigma_{c \max }}{\sigma_{c \min }}
$$

where $R_{c}$ is the anisotropy ratio of peak strength; $\sigma_{\mathrm{c} \max }$ is the maximum peak strength; and $\sigma_{\mathrm{cmin}}$ is the minimum peak strength. According to Figure 3, when the bedding orientation is $0^{\circ}$, the peak strength is the maximum $(94.90 \mathrm{MPa})$, and when the bedding angle is $45^{\circ}$, the peak strength is the minimum $(27.26 \mathrm{MPa})$; that is, $R_{c}$ is 3.48 , so the anisotropy ratio of the peak strength of layered rock is medium anisotropy.

According to the test results and equation (3), five independent parameters of layered rock can be obtained, as shown in Table 1.

After the transverse isotropy material parameters of layered rock are determined, more accurate engineering analysis can be carried out for the rock engineering with layered rock as the main lithologic characteristics, such as the change of rock stress state and the deformation of rock mass caused by tunnel excavation in layered rock stratum.

\subsection{Influence of Bedding Structure on Rock Fracture} Characteristics. The anisotropy of mechanical parameters of layered rock is closely related to its fracture mode. With the change of bedding orientation, the fracture of specimens shows different failure modes. In the uniaxial compression test, the specimen is subjected to load and goes through compaction stage, elastic stage, expansion stage, and failure stage. When the axial stress reaches the specimen peak strength, the accumulated energy inside the specimen is released suddenly and the failure occurs. Obvious macrocracks appear on the surface and run through the whole 


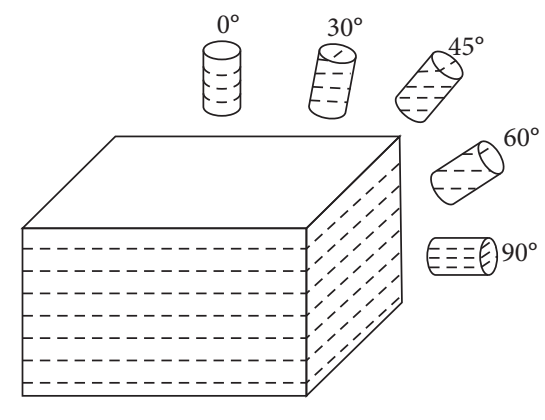

(a)

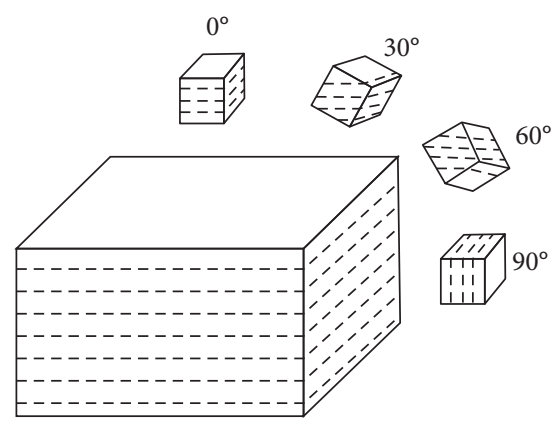

(b)

FIgURE 3: Schematic diagram of core sampling: (a) bedding orientations of the cylinder specimen; (b) bedding orientations of the cube specimen.

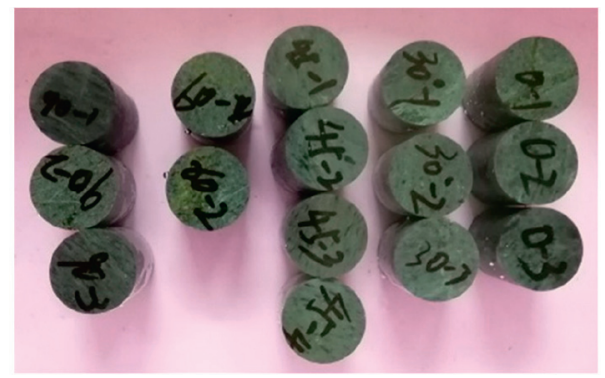

Figure 4: Cylinder specimens.

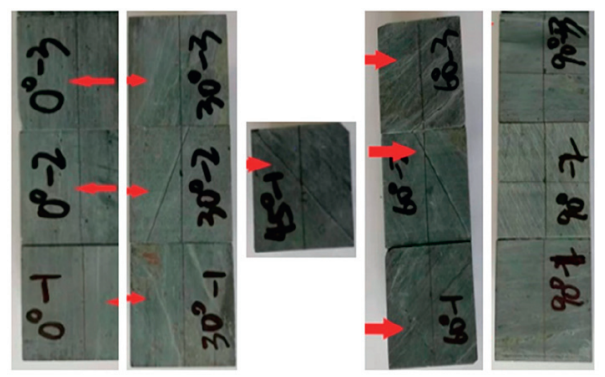

Figure 5: Cube specimens.

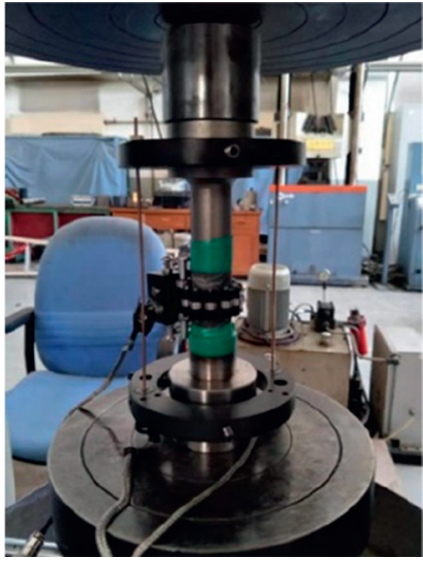

(a)

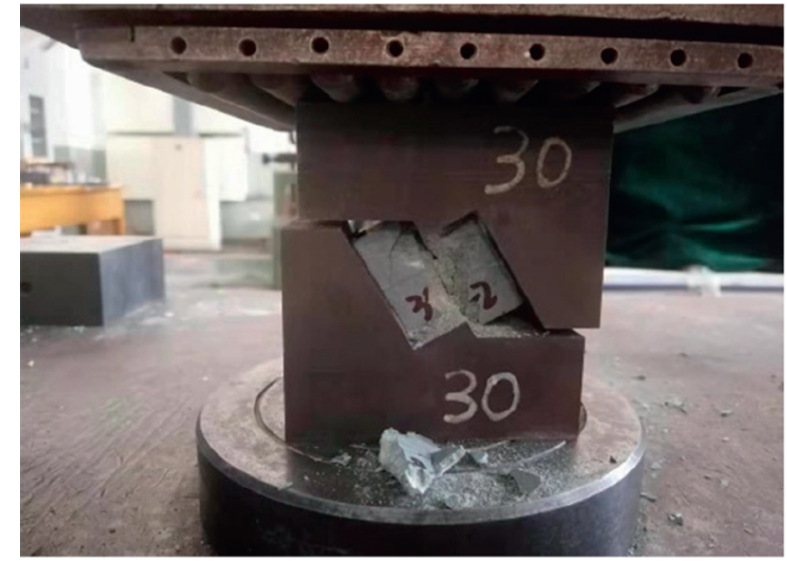

(b)

Figure 6: Diagram of test procedure: (a) uniaxial compression test process; (b) variable angle shear test process. 


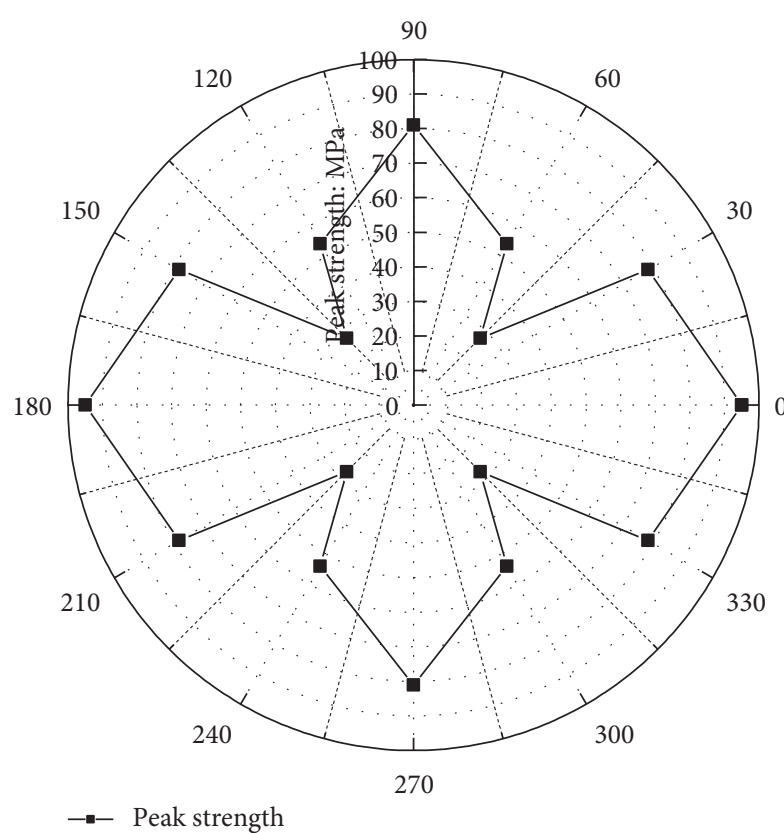

(a)

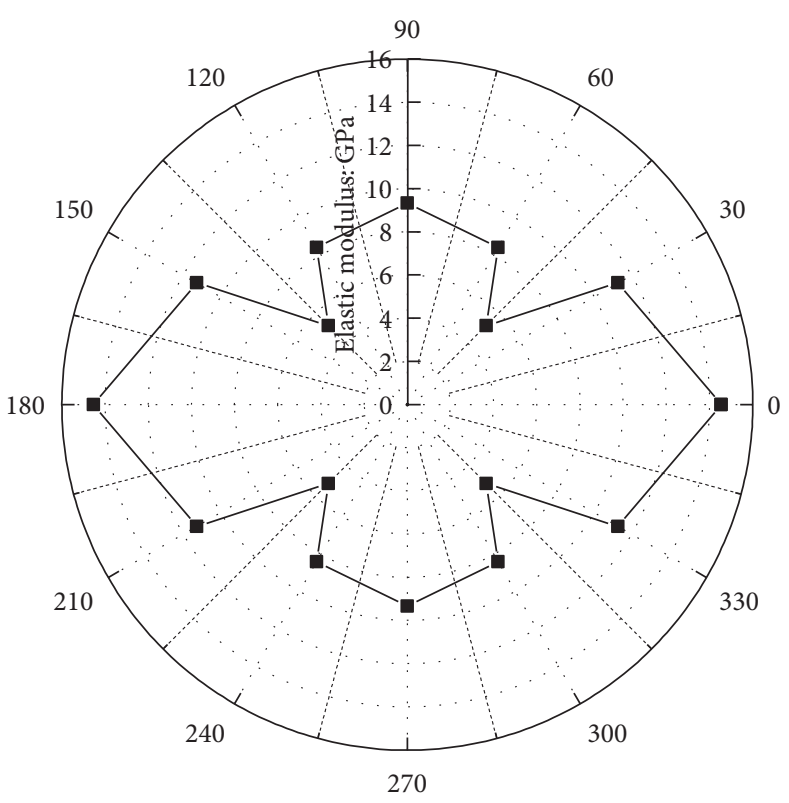

-_- Elastic modulus

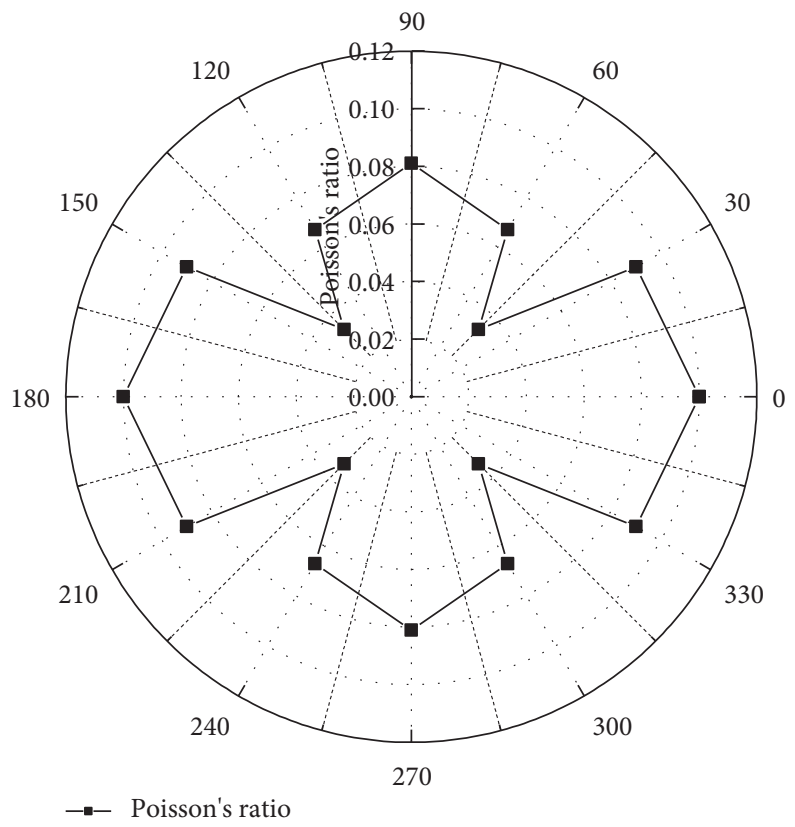

(c)

FIGURE 7: Mechanical parameters of layered rock with different bedding orientations: (a) peak strength of layered rock; (b) elastic modulus of layered rock; (c) Poisson's ratio of layered rock.

TABLE 1: Independent parameters of layered rock.

\begin{tabular}{lcccc}
\hline$E_{1}(\mathrm{GPa})$ & $E_{2}(\mathrm{GPa})$ & $v_{1}$ & $v_{2}$ & $G_{12}(\mathrm{GPa})$ \\
\hline 9.33 & 14.53 & 0.081 & 0.100 & 4.019 \\
\hline
\end{tabular}

specimen, forming multiple tensile and shear failure surfaces. The failure mode has obvious anisotropy. The failure modes of specimens with different bedding orientations are shown in Figure 8.
In general, the failure phenomena of all rock specimens have the characteristics of tension failure and shear failure, but the failure modes of rock specimens with different bedding orientations are different: 


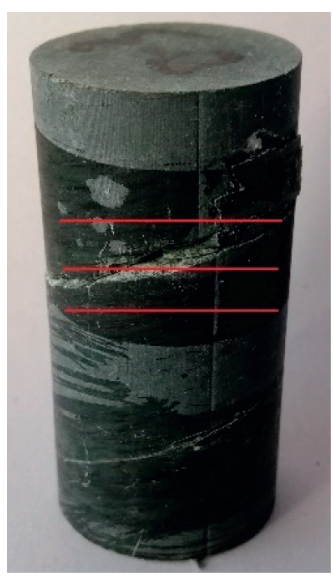

(a)

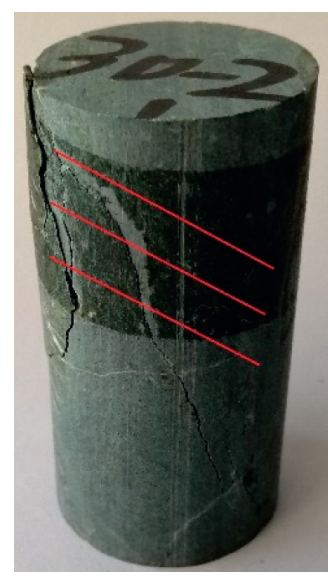

(b)

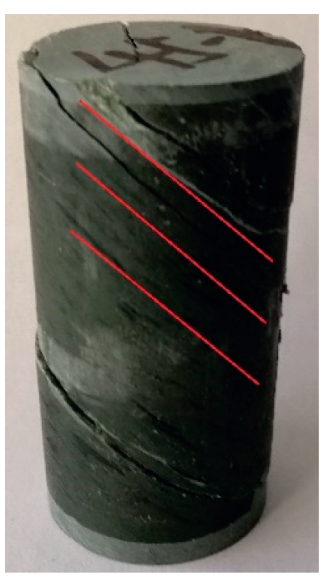

(c)

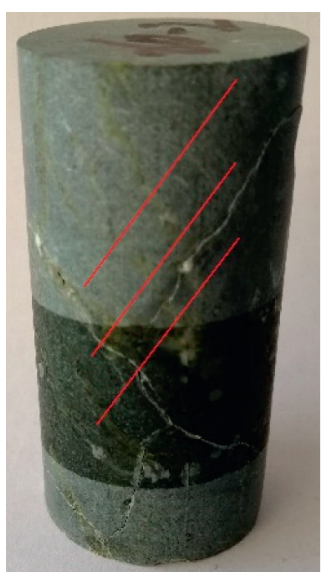

(d)

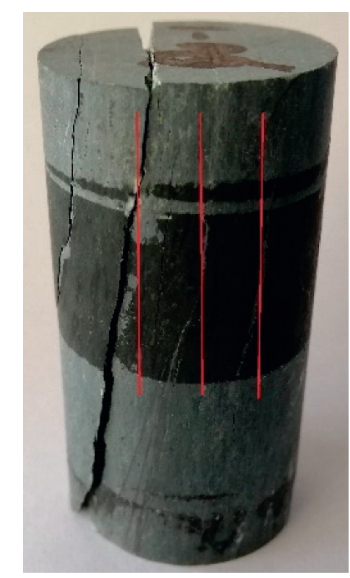

(e)

Figure 8: Uniaxial compression failure diagram of rock specimen: (a) $\beta=0^{\circ}$; (b) $\beta=30^{\circ}$; (c) $\beta=45^{\circ}$; (d) $\beta=60^{\circ}$; (e) $\beta=90^{\circ}$.

(1) $\beta=0^{\circ}$. Shear slip failure is the main failure form. For the specimens with $0^{\circ}$ bedding orientation, the crack direction is almost horizontal, only a few splitting cracks appear at the end of the specimen. The reason is that the loading direction is orthogonal to the bedding orientation, and the two ends of the specimen are subject to friction resistance, which limits its lateral deformation. The tensile failure through the weak plane of the bedding is formed in the middle of the specimen under the action of large lateral tension, which leads to the obvious shear slip phenomenon of the upper and lower parts of the specimen along the direction approximately parallel to the weak plane of the bedding, and causes the local surface fracture of the specimen. Under the action of large lateral tension in the middle of the specimen, the tensile failure through the weak plane of the bedding is formed, which leads to the obvious shear slip phenomenon of the upper and lower parts of the specimen.

(2) $\beta=30^{\circ}$ Tension and shear failure coexist. Under the action of external load, cracks develop along the weak plane of bedding until the specimen is destroyed. Under the action of load, the crack develops along the weak plane of bedding, forming a shear failure plane through the weak plane of bedding. At the same time, a tensile failure plane is formed along the weak plane of bedding on the surface of specimen, leading to local fracture. The crack develops along the axial direction, which is similar to the weak plane of bedding.

(3) $\beta=45^{\circ}$. Tension-shear composite failure between bedding weak plane and matrix: Under the action of load, two large angle shear cracks are formed on both sides of the specimen surface, which are different from the bedding orientation. During the loading process, the cracks gradually expand and finally form a tensile-shear composite failure plane along the bedding weak plane and through the weak plane of bedding and matrix. The failure plane runs through the two weak planes of bedding and intersects in the middle of the specimen. It shows multiple shear failure surfaces similar to $\mathrm{Y}$ shape.

(4) $\beta=60^{\circ}$. Shear failure is significant, and cracks almost all develop along the bedding orientation. Under the action of load, obvious shear failure is formed along the bedding weak plane at the upper and lower ends of the specimen, and many flat failure planes are formed at the upper and lower ends of the specimen, and the shear slip phenomenon parallel to the bedding weak plane occurs. This is because the shear stress on the bedding weak plane is greater than the shear strength of the specimen itself.

(5) $\beta=90^{\circ}$. Tension and shear failure coexist, but tension failure is the main failure form. The crack has a small vertical inclination and through the entire rock specimen. Under the action of load, the specimen gradually appears tensile cracks parallel to the bedding plane and finally forms the splitting tension failure along the bedding plane. The specimen has a tensile fracture plane which is obviously parallel to the bedding weak plane and runs through the matrix and through the ends of the entire rock specimen. Since the entire specimen is divided into two parts, one large and one small, their bearing capacity is reduced, respectively. The smaller part of the thin slab-shaped rock bears greater load than its own compressive strength. It leads to buckling instability and secondary rupture along the bedding weak plane.

From the above analysis, the main controlling factors of layered rock fracture with different bedding orientations can be obtained. It can be seen from the analysis that for any rock specimen failure mechanism with different bedding orientations, the bedding weak plane plays a leading role. Therefore, the bedding weak plane has become a key factor 
TABLE 2: Test results of variable angle shear of layered rock.

\begin{tabular}{|c|c|c|c|c|}
\hline Bedding orientation $\left({ }^{\circ}\right)$ & Failure load $(\mathrm{kN})$ & Shear stress $\tau(\mathrm{MPa})$ & Normal stress $\sigma(\mathrm{MPa})$ & Fixture angle $\left({ }^{\circ}\right)$ \\
\hline \multirow{3}{*}{0} & 65.87 & 25.03 & 68.78 & 20 \\
\hline & 25.42 & 14.12 & 24.46 & 30 \\
\hline & 15.36 & 10.97 & 13.07 & 40 \\
\hline \multirow{3}{*}{30} & 45.67 & 17.36 & 47.68 & 20 \\
\hline & 21.22 & 11.79 & 20.42 & 30 \\
\hline & 13.68 & 9.77 & 11.64 & 40 \\
\hline \multirow{3}{*}{60} & 32.69 & 12.42 & 34.13 & 20 \\
\hline & 14.12 & 7.84 & 13.59 & 30 \\
\hline & 12.24 & 8.74 & 10.42 & 40 \\
\hline \multirow{3}{*}{90} & 79.37 & 30.16 & 83.24 & 20 \\
\hline & 27.91 & 15.51 & 7.84 & 30 \\
\hline & 19.82 & 14.16 & 16.87 & 40 \\
\hline
\end{tabular}

affecting the anisotropy of the failure mechanism of layered rock specimens.

The elastic modulus is an important performance parameter of engineering materials. From the macroscopic point of view, the elastic modulus is a measure of the ability of an object to resist elastic deformation. The elastic modulus of the material can be affected by all the factors that affect the bonding strength. When there is bedding plane in the rock, the bedding plane belongs to the weak plane of the rock, so compared with the matrix material, the stiffness of the weak plane of bedding is small and the deformation is large. Compared with the rock mass without bedding plane, this kind of rock is prone to failure under uniaxial compression.

The variation of elastic modulus and Poisson's ratio with bedding orientation is shown in Figures 7(b) and 7(c). It can be seen from Figure 7(b) that under the uniaxial compression test of layered rock, the elastic modulus first decreases and then increases with the increase in the angle between bedding orientation and horizontal plane. On the whole, it is similar to the change trend of compressive strength and also presents a U-shaped change trend of high on both sides and low in the middle. When the bedding orientation is $0^{\circ}$ (parallel to the bedding), the elastic modulus of layered rock is the largest; when the bedding orientation is $45^{\circ}$, the elastic modulus of layered rock is the smallest. The vertical bedding is easy to be tensioned and split along the bedding plane under the action of axial stress; in parallel bedding, because the axial stress is perpendicular to the bedding plane, the stacking reaction occurs on the bedding plane during loading, resulting in the compression of the bedding plane, and the axial strain changes relatively large. The deformation modulus is used to define the anisotropy ratio of layered rock:

$$
R_{E}=\frac{E_{\max }}{E_{\min }},
$$

where $R_{E}$ is the anisotropy ratio of the elastic modulus; $E_{\max }$ is the maximum elastic modulus of layered rock between $0^{\circ}$ and $90^{\circ}$ bedding orientation; and $E_{\min }$ is the minimum elastic modulus of layered rock between $0^{\circ}$ and $90^{\circ}$ bedding orientation. The ratio of the maximum to the minimum is
2.8, which is the anisotropy ratio of the deformation modulus of layered rock.

Poisson's ratio of layered rock specimens, as shown in Figure $7(\mathrm{c})$, is similar to the compressive strength and elastic modulus of layered rock. It shows a U-shaped change trend of high on both sides and low in the middle. On the whole, Poisson's ratio decreases or increases but the amplitude is small at the low bedding orientation (from $0^{\circ}$ to $30^{\circ}$ ) and the high bedding orientation (from $60^{\circ}$ to $90^{\circ}$ ), which indicates that the bedding anisotropy is weak at this time; at the slightly higher bedding orientation (from $30^{\circ}$ to $60^{\circ}$ ), Poisson's ratio changes greatly with the bedding orientation, which indicates that the bedding anisotropy is strong at this time.

4.3. Effect of Bedding Plane on Rock Shear Properties. The results of the variable angle shear test of layered rock are shown in Table 2.

According to the measured data of normal stress and shear stress in Table 2, the fitting results are shown in Figure 9.

It can be seen from Figure 9 that the overall fitting degree of the Mohr-Coulomb fitting curve is very high. According to Figure 9, the cohesion and internal friction angles with different bedding orientations can be obtained, and the results are shown in Table 3.

According to the above, the cohesion and internal friction angle with different bedding orientations are obtained, and the relationship among bedding orientation, cohesion, and internal friction angle is established, as shown in Figure 10.

It can be seen from Figure 10 that with the increase in the angle between bedding plane and horizontal plane, the cohesion and internal friction angle of layered rock specimens first decrease and then increase, showing a U-shaped variation trend of high at both sides and low in the middle similar to the compressive strength curve. When the bedding orientation is $0^{\circ}$ and $90^{\circ}$, the cohesion and internal friction angle are relatively large, and when the bedding orientation is $60^{\circ}$, they are relatively small.

The failure modes are shown in Figure 11. When the bedding orientation is $0^{\circ}$, there is the composite failure of tension through weak bedding plane and shear slip along 


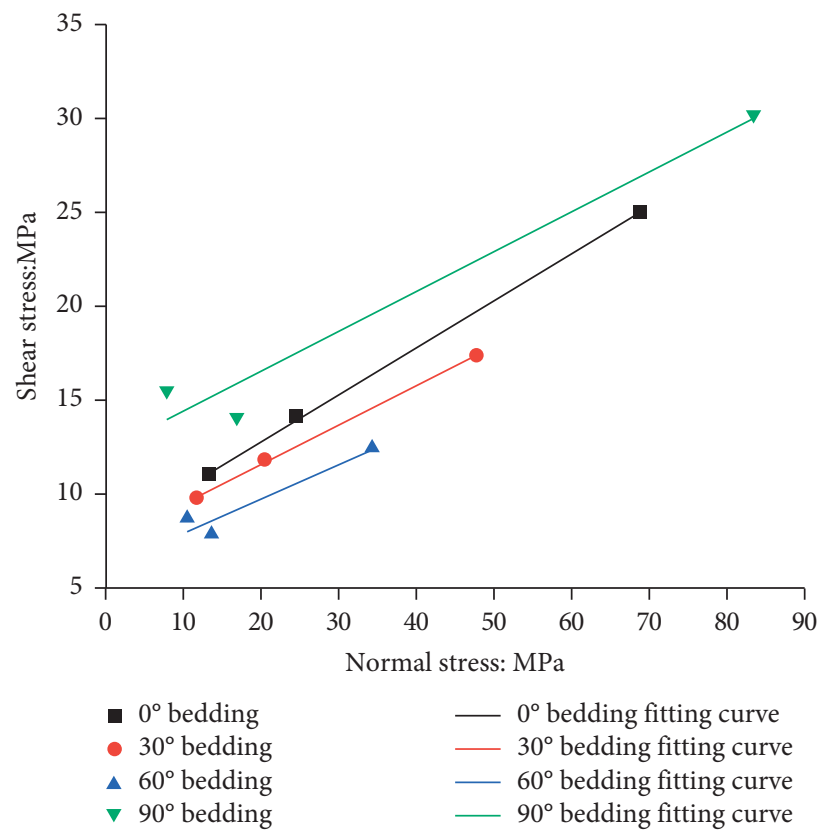

FIgUre 9: Mohr-Coulomb curves of shear strength of layered rocks under different loading modes.

TABLE 3: Cohesion and internal friction angle with different bedding orientations.

\begin{tabular}{lccc}
\hline Bedding orientation $\left({ }^{\circ}\right)$ & Fitting curve & Cohesion $(\mathrm{MPa})$ & Internal friction angle $\left(^{\circ}\right)$ \\
\hline 0 & $\tau=0.25 \sigma+7.82$ & 7.82 & 14.07 \\
30 & $\tau=0.20 \sigma+7.42$ & 7.42 & 11.80 \\
60 & $\tau=0.18 \sigma+6.19$ & 6.19 & 10.18 \\
90 & $\tau=0.25 \sigma+9.43$ & 9.43 & 13.98 \\
\hline
\end{tabular}

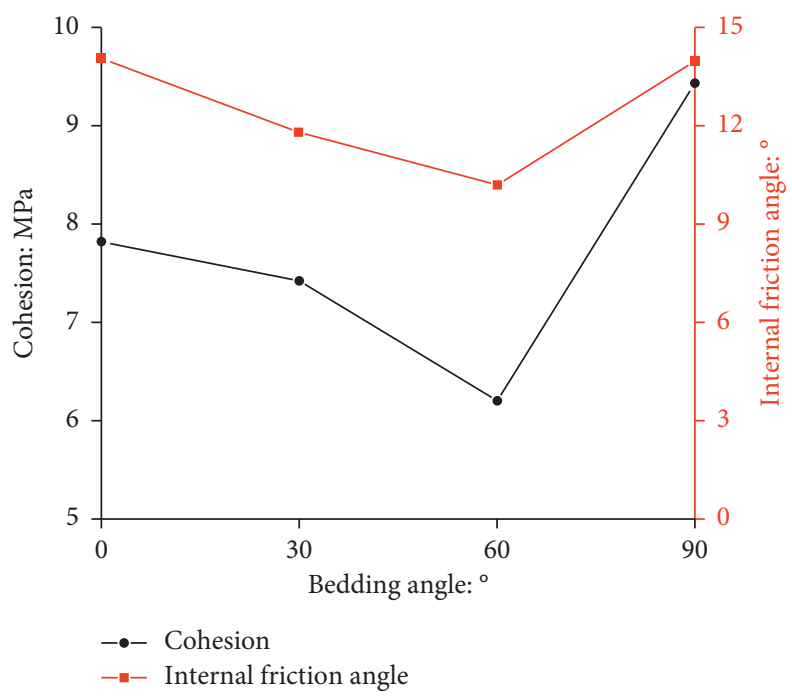

Figure 10: Variation of cohesion and internal friction angle with bedding orientation.

bedding plane; when the bedding orientation is $30^{\circ}$, the shear failure along the weak bedding plane and through the bedding plane occurs; when the bedding orientation is $60^{\circ}$, the shear slip failure along the weak bedding plane occurs, and the ends present the phenomenon of crossing the matrix; when the bedding orientation is $90^{\circ}$, the splitting tensile failure along the weak bedding plane occurs, and the failure surface is relatively regular. 


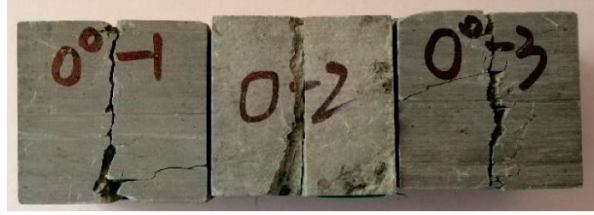

(a)

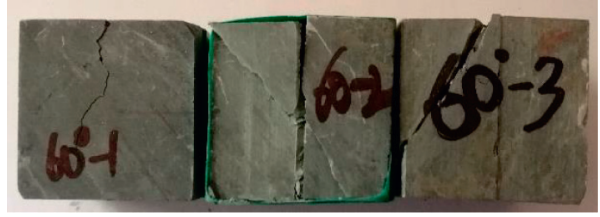

(c)

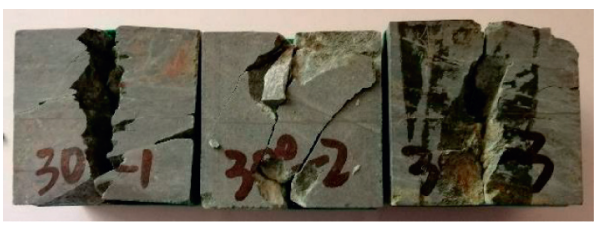

(b)

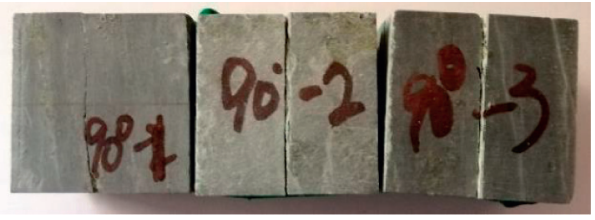

(d)

FIgURE 11: Variable angle shear failure diagram with different bedding orientations: (a) $\beta=0^{\circ}$; (b) $\beta=30^{\circ}$; (c) $\beta=60^{\circ}$; (d) $\beta=90^{\circ}$.

\section{Conclusions}

In this paper, uniaxial compression and variable angle shear tests are carried out on rocks with different bedding orientations. By analyzing the evolution trend of mechanical parameters and failure modes of with different bedding orientations, the following conclusions are drawn:

(1) The compressive strength of layered rock has obvious anisotropy. With the increase in the angle between bedding orientation and horizontal plane, the uniaxial compressive strength first decreases and then increases and generally presents a U-shaped variation trend of high on both sides and low in the middle. $R_{C}=4.8$, indicating that the specimen is moderately transverse isotropic.

(2) The elastic modulus and Poisson's ratio of layered rock first decrease and then increase with the increase in the bedding orientation. On the whole, the variation trend of both is similar to the compressive strength of layered rock.

(3) In the uniaxial compression test of layered rock, the anisotropy of failure mechanism of layered rock is closely related to the bedding orientations, which is mainly reflected in different failure modes with different bedding orientations. On the whole, the failure modes of Figure 1specimens can be divided into three types: the fracture tensile failure parallel to the weak plane of bedding; the shear slip failure along bedding weak plane; and tension-shear composite failure between bedding weak plane and matrix.

(4) The cohesion and internal friction angle of layered rock specimens show a U-shaped change trend of high at both sides and low in the middle similar to the compressive strength curve. For the variable angle shear test, the $0^{\circ}$ specimen shows the composite failure of tension through the bedding weak plane and shear slip along the bedding plane. Shear failure along bedding plane and through bedding plane occurs in the $30^{\circ}$ specimen. The shear slip failure along the bedding plane occurs in the $60^{\circ}$ specimen, and the end of the specimen runs through the matrix. The $90^{\circ}$ specimen shows splitting tensile failure along the bedding weak plane.

\section{Data Availability}

The data used to support the findings of this study are available from the corresponding author upon request.

\section{Conflicts of Interest}

The authors declare that there are no conflicts of interest regarding the publication of this paper.

\section{Acknowledgments}

The authors would like to thank for funds from the National Natural Science Foundation of China (51774021 and 52074021) and the Key Research Development Program of Shandong Province, China (2019SDZY05).

\section{References}

[1] E. Q. Li, H. C. Zhang, L. F. Zhang, T. Y. Zhu, J. G. Lu, and J. L. Feng, "Brazilian splitting test and numerical study of carbonaceous plate with different bedding dip," Rock and Soil Mechanics, vol. 41, no. 9, pp. 2869-2879, 2020.

[2] Z. X. Luo, W. W. Peng, Y. Y. Wei, D. Q. Hou, and Y. Yang, "Experimental study on mechanical properties of rock mass in underground powerhouse of Lianghekou Hydropower Station," Chinese Journal of Underground Space and Engineering, vol. 13, no. S2, pp. 565-570, 2017.

[3] C. C. Wang, J. T. Li, H. Lin, J. Liao, P. X. Wang, and S. Q. Wang, "Mechanical characteristics of uniaxial compression anisotropy of plate," Journal of Central South University, vol. 47, no. 11, pp. 3759-3764, 2016.

[4] H. Wang, F. Ren, and Y. Chang, "Effect of bedding angle on tunnel slate failure behavior under indirect tension," Geomatics, Natural Hazards and Risk, vol. 11, no. 1, pp. 428-445, 2020.

[5] Y. D. Yang, F. F. Jia, B. Liang, D. Xia, and C. S. Wu, "Experimental study on the influence of bedding dip angle on 
rock shear strength parameters," Mining Technology, vol. 19, no. 6, pp. 77-81, 2019.

[6] L. Xia, J. S. Yao, and L. Jiang, "Effect of bedding characteristics on shear mechanical properties of layered rock," Journal of Water Resources and Architectural Engineering, vol. 18, no. 1, pp. 37-43+69, 2020.

[7] W. Ding, J. Wang, Q. H. Jiang, and X. H. Chu, "Basic properties and failure criteria of transversely isotropic shale," China Water Transport, vol. 16, no. 3, pp. 207-212, 2016.

[8] J. T. Li, H. W. Wang, and H. Lin, "Correlation between bedding orientation and compressive strength and fracture toughness of transversely isotropic plate," Journal of Hunan University, vol. 43, no. 7, pp. 126-131, 2016.

[9] Y. S. Liu, H. L. Fu, Y. M. Wu, J. Y. Rao, Q. Yin, and W. Yuan, "Experimental study on elastic parameters and compressive strength of transversely isotropic rocks," Journal of Central South University, vol. 44, no. 8, pp. 3398-3404, 2013.

[10] Q. Gao, J. Tao, J. Hu, and X. Yu, "Laboratory study on the mechanical behaviors of an anisotropic shale rock," Journal of Rock Mechanics and Geotechnical Engineering, vol. 7, no. 2, pp. 213-219, 2015.

[11] W. Liu, Y. W. Zeng, X. Chen, and S. L. Ren, "Discussion on determination method of tensile strength of layered rock," Journal of Water Resources and Architectural Engineering, vol. 16, no. 2, pp. 126-130, 2018.

[12] X. Tan, H. L. Fu, C. Chen, M. H. Zhao, and Y. S. Liu, "Numerical analysis of tunnel stability in layered rock," Journal of Railway Science and Engineering, vol. 13, no. 6, pp. 1108-1113, 2016.

[13] T. Xu, P. G. Ranjith, P. L. P. Wasantha, J. Zhao, C. A. Tang, and W. C. Zhu, "Influence of the geometry of partially-spanning joints on mechanical properties of rock in uniaxial compression," Engineering Geology, vol. 167, pp. 134-147, 2013.

[14] L. Xia, Y. W. Zeng, and S. Zhang, "Study on the influence of meso parameters of bedding plane on the strength characteristics of layered rock," Journal of Yangtze River Scientific Research Institute, vol. 33, no. 7, pp. 68-75, 2016.

[15] H. L. Fu, J. B. Zhang, Y. M. Wu, Z. Huang, Y. Shi, and C. Y. Wang, "Experimental study on failure types and uniaxial compressive strength of plate under low temperature freezing," Journal of Central South University, vol. 48, no. 11, pp. 3051-3059, 2017.

[16] Q. Yuan, B. Y. Xue, C. Tan, L. L. Li, L. Zhuo, and K. X. Huang, "Study on rate effect mechanical properties of uniaxial compressive strength of layered rock," Mining Research and Development, vol. 39, no. 8, pp. 58-62, 2019.

[17] G. L. Shen and G. K. Hu, Mechanics of Composite Materials, Tsinghua University Press, Beijing, China, 2006.

[18] S. Z. Li, P. Sha, F. Q. Wu, and J. Wu, "Analysis of anisotropic characteristics of layered rock deformation," Rock and Soil Mechanics, vol. 39, no. S2, pp. 366-373, 2018.

[19] H. W. Ye, J. Cai, T. Lei, C. Ran, and W. X. Ning, "Progressive shear failure anisotropy of plate and its numerical model," Chinese Journal of Underground Space and Engineering, vol. 14, no. 4, pp. 945-954, 2018.

[20] M. P. Huang, J. T. Li, J. Zhang, C. C. Wang, and S. Q. Wang, "Experimental study on anisotropic creep properties of plate," Journal of Central South University, vol. 48, no. 8, pp. 22102216, 2017.

[21] T. Ramamurthy, G. V. Rao, and J. Singh, "Engineering behaviour of phyllites," Engineering Geology, vol. 33, no. 3, pp. 209-225, 1993. 